\title{
Protection by flavonoids against anthracycline cardiotoxicity: from chemistry to clinical trials
}

\author{
Aalt Bast - Guido R. M. M. Haenen · Anna M. E. Bruynzeel • \\ Wim J. F. Van der Vijgh
}

Published online: 26 May 2007

(C) Humana Press Inc. 2007

\begin{abstract}
Cardiotoxic side-effects of doxorubicin limit the clinical use of this anti-cancer agent. Iron chelators have been studied as protectors against doxorubicin-induced cardiotoxicity. These iron chelators do not provide optimal protection and have certain drawbacks. We therefore looked for new protectors and decided that these new compounds should combine iron chelating and antioxidant activity. Flavonoids appeared to possess those combined iron chelating and antioxidant properties. Quantum chemical evaluation of radical stabilization and determination of physico-chemical properties of a series of flavonoids brought our attention to the semi-synthetic flavonoid 7monohydroxyetylrutoside (monoHER). Both in vitro (using an electrically paced mouse left atrium model) and in vivo (using a mouse ECG telemetry model) experiments corroborated the protective effect of monoHER. MonoHER also showed anti-inflammatory properties. A subsequent clinical phase I study showed that an i.v. dose of $1,500 \mathrm{mg} /$ $\mathrm{m}^{2}$ is a feasible and safe dose to be evaluated in a phase II study to investigate the protective properties of monoHER against doxorubicin-induced cardiotoxicity in cancer patients.
\end{abstract}

Keywords Doxorubicin · Cardiotoxicity · Flavonoids · Antioxidants $\cdot$ Telemetry

A. Bast $(\bowtie)$ - G. R. M. M. Haenen · W. J. F. Van der Vijgh Department of Pharmacology and Toxicology, Faculty of Medicine, University of Maastricht, P.O. Box 616, 6200 MD Maastricht, The Netherlands

e-mail: a.bast@farmaco.unimaas.nl

A. M. E. Bruynzeel - W. J. F. Van der Vijgh

Department of Medical Oncology, VU University Medical

Center, 1081 HV Amsterdam, The Netherlands

\section{Molecular mechanism of the cardiotoxicity of doxorubicin}

The clinical use of doxorubicin, a widely used anthracycline is hampered by the common side-effects observed upon use of the majority of anti-cancer agents, viz. bone marrow suppression, alopecia, nausea and vomiting. Doxorubicin-induced bone marrow suppression can now be reduced by the use of haematopoietic growth factors. In addition to these rather common acute toxicities, anthracyclines contain the risk of causing a cardiomyopathy. In fact, the development of cumulative dose-related cardiotoxicity currently forms the major limitation of doxorubicin use in the clinic.

The production of free radicals as by-product of doxorubicin metabolism is considered to be the main mechanism of doxorubicin-induced cardiotoxicity. The quinone moiety of doxorubicin is converted into a semiquinone form by the acquisition of one electron. This conversion can occur either enzymatically or nonenzymatically. The enzymatic reduction of the doxorubicin quinone ring is performed by cytochrome P450 reductase, NADH dehydrogenase and cytochrome P450 [1]. The produced semiquinone form is oxidized by molecular oxygen, which yields back doxorubicin in its quinone form with concomitant production of superoxide anion radicals. This process is called redox cycling. Superoxide radicals can dismutate either enzymatically catalyzed by superoxide dismutase or, albeit with a lower rate, spontaneously. From this dismutation hydrogen peroxide is formed. This may lead to toxicity. Iron ions have been suggested to play a crucial role in this process. Not only because iron reacts with hydrogen peroxide to form the reactive hydroxyl radical but also because $\mathrm{Fe}^{3+}$ may form complexes with doxorubicin. The theory on the iron-dependent formation 
of free radicals by doxorubicin semiquinones is supposed to be the most prevailing one to explain the cardiotoxicity. An internal electron shift may give reduction of iron, which subsequently delivers this electron to molecular oxygen yielding superoxide anion radicals.

\section{The need for new protectors}

Iron chelators have been studied as protectors against doxorubicin-induced cardiotoxicity. The bispiperazinedione ICRF 187 has been studied extensively. ICRF 187 is also known as dexrazoxane and is the more water soluble (+)enantiomorph of the racemic mixture ICRF-159, which was originally developed as a conventional antineoplastic agent [2]. In phase I trials using a variety of schedules in both adults and children, dose-limiting toxicities on most schedules were myelosuppression, except in children, in whom the major dose-limiting toxicity was hepatotoxicity [3]. In addition, research conducted at the same time as the initial phase I studies showed that the divalent chelating properties of ICRF-159 and 187 could protect animals from the cardiotoxicity induced by anthracyclines [4, 5]. This further corroborated the catalytic toxic role of iron ions in the doxorubicin-induced cardiotoxicity. There are several disadvantages associated with the use of ICRF-187. ICRF187 exerts a dose-dependent myelosuppression, which may limit its addition to chemotherapy. Moreover, controversy exists as to whether ICRF-187 decreases the antitumour activity of doxorubicin. ICRF-187 is a prodrug which requires hydrolysis to achieve the active form. Finally, ICRF198, the hydrolyzed form of ICRF-187 is an EDTA-like chelator. This implies that because of stoichiometrical restrictions the drug lacks the ability to occupy all six coordination sites of iron. Consequently, iron remains catalytically active to generate oxygen radicals. Besides iron chelators as ICRF-187 and for example deferoxamine, many other compounds have been evaluated for their potential to reduce doxorubicin-induced cardiotoxicity, based on a perceived ability to modulate some of the biochemical alterations that accompany doxorubicin administration. The list of compounds includes adenosine, anti-histamine agents (both $\mathrm{H}_{1}$ and $\mathrm{H}_{2}$ blockers), beta-adrenoceptor antagonists, amrinone, milrinone, fructose-1,6-diphosphate, inosine, ibuprofen, dextran, methylprednisone, salts of bismuth, zinc and calcium, tetracycline antibiotics and a number of iron chelators as deferoxamine, ICRF-187. In addition, various antioxidants have been applied as vitamin E, curcumin, lipoic acid and venoruton.

In view of the suggested molecular mechanism involved in doxorubicin-induced cardiotoxicity we searched for protectors which combine iron-chelating and oxygen radical scavenging properties. Moreover, the novel protector should not interfere with the cytostatic activity of doxorubicin.

\section{The choice for flavonoids}

A large series of flavonoids from several subclasses were screened by quantum chemical calculation (Fig. 1) and physico-chemical characterization to find antioxidants with both iron chelating and oxygen radical scavenging properties [6-8]. To study the direct antioxidant action of the flavonoids, the compounds were tested in the iron-independent liver microsomal lipid peroxidation, which was induced with azobisamidinopropane (ABAP), a hydrophilic azo-initiator. ABAP generates a constant radical flow in the water phase of the lipid peroxidation system. An excess of EDTA was added to inactivate all traces of iron. A good correlation was found between the inhibition ( $\mathrm{pIC}_{50}$-value) of the ABAP-induced lipid peroxidation by the flavonoids and their half-peak oxidation potential (Ep/2) (Fig. 2). In contrast to the ABAP-induced lipid peroxidation where iron does not play a role in the initiation of lipid peroxidation, iron is strongly involved in the lipid peroxidation
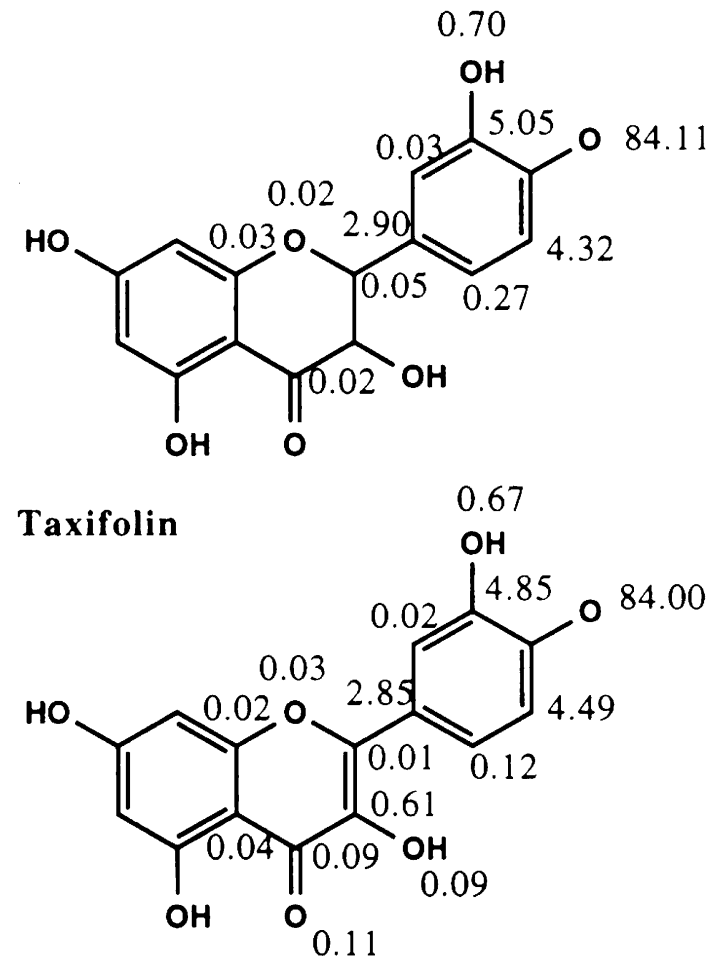

\section{Quercetin}

Fig. 1 Spin distribution of the quercetine and taxifoline radical. Small changes in the molecule (in this case a 2-3 double bond) lead to variation in the spin distribution and to changes in the antioxidant activity of the molecule 


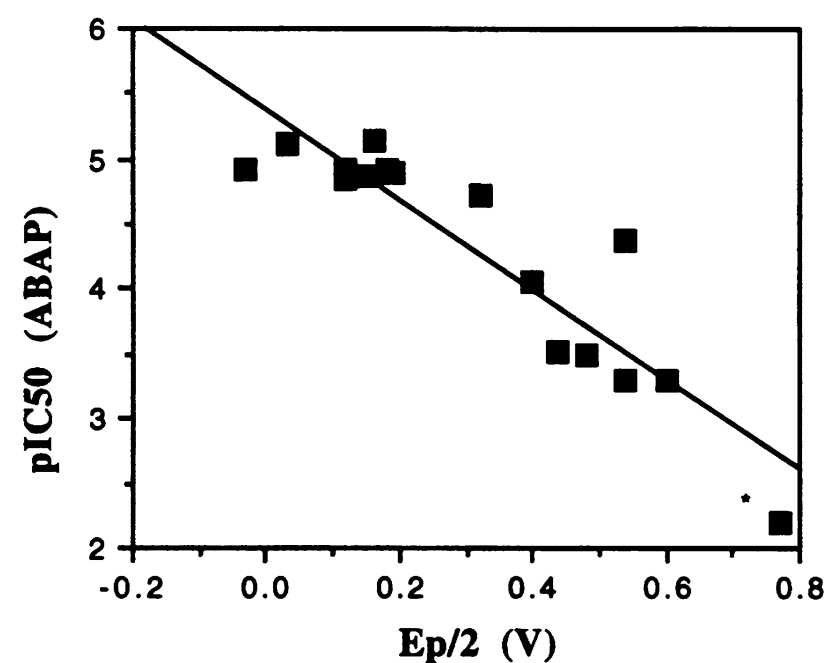

Fig. 2 Correlation between inhibition $\left(\mathrm{pIC}_{50}\right.$-value) of ABAPinduced lipid peroxidation by several flavonoids and their half-peak oxidation potential. Lipid peroxidation was induced in mouse liver microsomes with $10 \mathrm{mmol} / \mathrm{l} \mathrm{ABAP}$ in the presence of $100 \mu \mathrm{mol} / \mathrm{l}$ $\mathrm{Na}_{2} \mathrm{EDTA}$ at $37^{\circ} \mathrm{C}$ for $1.5 \mathrm{~h}$

induced with $\mathrm{Fe}^{2+} /$ ascorbic acid. Also in the enzymatic doxorubicin induced lipid peroxidation iron is suggested to play a role. The correlations of the inhibition of the lipid peroxidation processes in which iron is involved are weaker than the correlation obtained in the iron-independent lipid peroxidation process (Fig. 2). This suggests that besides the direct radical scavenging effect also the iron chelating effect of the flavonoids is involved in their antioxidant action.

\section{Protection against negative inotropic action ex vivo and in vitro}

We subsequently tested a selection of promising flavonoids which possess combined antioxidant and iron-chelating properties in a series of in vitro and ex vivo organ bath studies [9-11]. The flavonoid 7-monohydroxyethylrutoside was able to protect almost completely (93\%) against the negative inotropic effect of $30 \mu \mathrm{M}$ doxorubicin. This concentration of doxorubicin gives 50\% inhibition of the inotropy of the isolated electrically paced mouse left atrium (Fig. 3).

\section{Protection against in vivo changes induced by doxorubicin in the ECG of mice}

The promising protector 7-monohydroxyethylrutoside was further evaluated in vivo in a comparative study with ICRF-187. Balb/c mice of 20-25 g were equipped with a

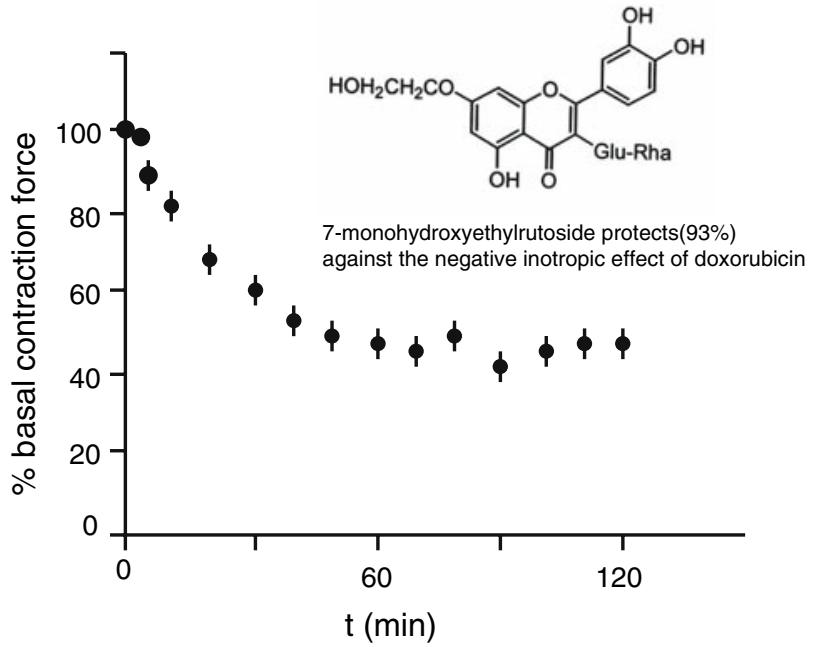

Fig. 3 Negative inotropic action of $30 \mu \mathrm{mol} / 1$ doxorubicin in the isolated mouse left atrium. Maximal protection by pre-incubation with 7-monohydroxyethyl rutoside was $93 \%$

telemeter to measure ECG (Fig. 4). They were given 6 i.v. doses of doxorubicin $(4 \mathrm{mg} / \mathrm{kg})$ at weekly intervals. ICRF$187(50 \mathrm{mg} / \mathrm{kg})$ or 7 -monohydroxyethylrutoside at 100 , 250 or $500 \mathrm{mg} / \mathrm{kg}$ were given i.p. $1 \mathrm{~h}$ prior to doxorubicin administration [12, 13]. A saline and a 7-monohydroxyethylrutoside treated group served as control. At the end of the study (week 8) the ST-interval of the ECG had increased by $16.7 \pm 2.7 \mathrm{~ms}$ (mean \pm s.e. mean) in the doxorubicin-treated mice. At the same time, the ST interval had increased by only $1.8 \pm 0.9 \mathrm{~ms}$ in ICRF-187 co-medicated mice and in 7-monohydroxyethylrutoside co-medicated mice by only $7.8 \pm 1.7 \mathrm{~ms}, \quad 4.6 \pm 0.7 \mathrm{~ms}$, $1.7 \pm 0.8 \mathrm{~ms}$ for 100,250 and $500 \mathrm{mg} / \mathrm{kg}$, respectively. The ECG of the control animals did not change during the study. The QRS complex did not change in either group (Fig. 4).

\section{Lack of interference with the tumour growth inhibition in vitro and in vivo}

Three cell lines were used i.e. the human ovarian cell lines A2780 and OVCAR-3 and the human breast cancer cell line MCF-7 to check for the effect of the selected flavonoid 7-monohydroxyethylrutoside on the IC50 values of growth inhibition by doxorubicin (Table 1). A2780 cells were approximately 10 -fold more sensitive to doxorubicin than MCF-7 and OVCAR-3 cells as measured from the IC50 values of $2.05 \times 10^{-8}, 2.09 \times 10^{-7}$ and $3.28 \times 10^{-7} \mathrm{M}$, respectively. The compound 7 -monohydroxyethylrutoside was not cytotoxic at concentrations of 50 and $100 \mu \mathrm{M}$ (Table 1). More importantly, 7-monohydroxyethylrutoside 
Fig. 4 Dose dependent protection by 7-monoHER (i.p.) on the ST-interval lengthening of the ECG of mice treated with doxorubicin. Image on the right shows the X-ray of a mouse with a transmitter to measure the ECG via telemetry
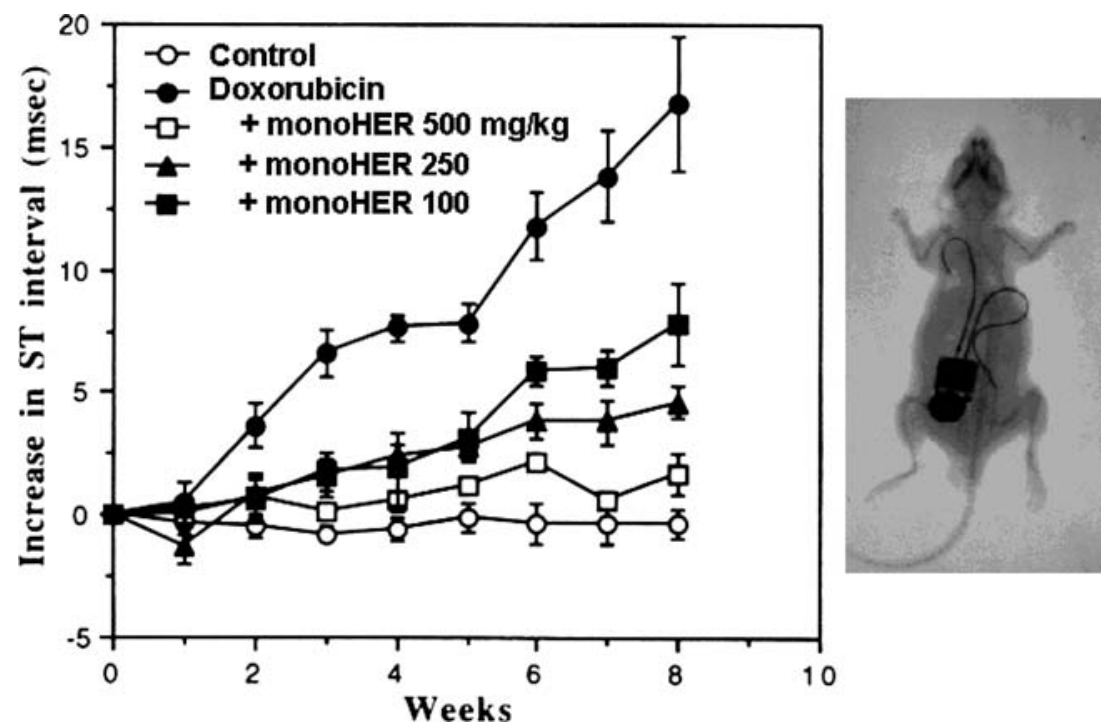

Table 1 IC50 values of growth inhibition of various tumour cell lines by doxorubicin in absence and presence of 50 or $100 \mu \mathrm{M}$ of 7 monohydroxyetylrutoside

\begin{tabular}{llll}
\hline & $\mathrm{A} 2780\left(\times 10^{-8} \mathrm{M}\right)$ & $\mathrm{MCF}-7\left(\times 10^{-7} \mathrm{M}\right)$ & $\mathrm{OVCAR}-3\left(\times 10^{-7} \mathrm{M}\right)$ \\
\hline Doxorubicin & $2.05 \pm 0.66$ & $2.09 \pm 0.75$ & $3.28 \pm 1.70$ \\
Doxorubicin $+50 \mu \mathrm{M} 7$-monoHER & $2.57 \pm 1.95$ & $1.11 \pm 0.04$ & $4.29 \pm 1.95$ \\
Doxorubicin $+100 \mu \mathrm{M} 7$-monoHER & $2.00 \pm 1.82$ & $2.10 \pm 0.22$ & $5.67 \pm 2.37$ \\
\hline
\end{tabular}

Data are expressed as mean \pm SD of at least three independent experiments performed in triplicate

did not significantly influence the IC50 of doxorubicin in the investigated cell lines (Table 1).

The antitumour activity of doxorubicin $(8 \mathrm{mg} / \mathrm{kg}$ i.v. twice weekly) in A2780 xenografts and OVCAR-3 (Fig. 5) xenografts in nude mice was not decreased by 7-monohydroxyethylrutoside, administered $1 \mathrm{~h}$ before doxorubicin in a dose schedule of $500 \mathrm{mg} / \mathrm{kg}$ i.p. 2 or 5 days per week [13].

\section{Involvement of iron, inflammation and superoxide anion radicals}

Although the initial choice for selecting 7-monohydroxyethylrutoside was among others based on its iron-chelating properties, we recently obtained data, which question the involvement of iron in oxidative stress mediated toxicity in doxorubicin. We compared several well-known iron chelators (ICRF-187, 7-monohydroxyethylrutoside, deferoxamine and pyridoxal isonicotinoyl hydrazone) and found that only ICRF-187 and 7-monohydroxyethylrutoside protected the human lung adenocarcinoma cells A549 against doxorubicin-induced oxidative stress while other chelators did not [14].
Human umbilical cord vascular endothelial cells (HUVECs) were incubated with increasing concentrations of doxorubicin (up to $25 \mu \mathrm{M}$ ) to investigate whether doxorubicin could induce an inflammatory response in vitro. It appeared that proliferating HUVECs were more sensitive to doxorubicin (IC50 value of $60 \pm 21 \mathrm{nM}$ ) than resting cells (IC50 value of $4.0 \pm 0.3 \mu \mathrm{M}$ ) [15]. Doxorubicin also increased the adhesion of neutrophils, which was accompanied by overexpression of VCAM and E-selectin. Treatment with $1 \mathrm{mM}$ of 7-monohydroxyethylrutoside prevented this overexpression. The increased levels of adhesion molecules probably explain the stimulation of neutrophil adhesion to the endothelial cells by $0.6 \mu \mathrm{M}$ doxorubicin. The flavonoid 7-monohydroxyethylrutoside $(1 \mathrm{mM})$ prevents the doxorubicin-stimulated neutrophil adhesion [15].

This protective effect of the flavonoid against inflammation was also observed recently in a study on ischaemiareperfusion in mice [16]. In this study, heart ischaemia was induced for $30 \mathrm{~min}$ by ligating the left anterior descending coronary artery. Afterwards, the ligature was removed and reperfusion was allowed for 6 or $24 \mathrm{~h}$. The protector 7monohydroxyethylrutoside was given i.p. $(500 \mathrm{mg} / \mathrm{kg}) 1 \mathrm{~h}$ before reperfusion and strongly attenuated myocardial 


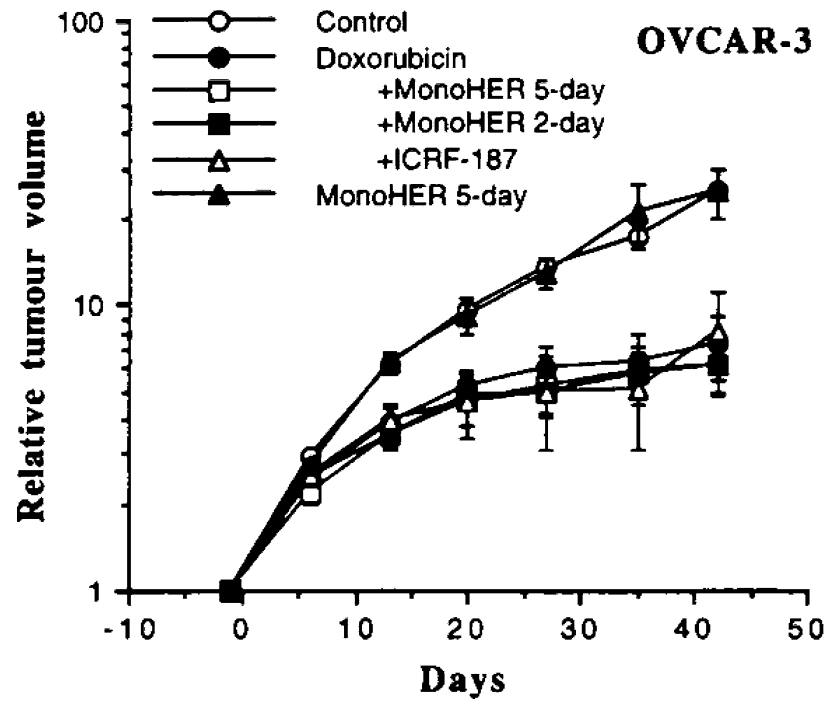

Fig. 5 Growth of OVCAR-3 xenografts in nude mice and the influence of the cardioprotectors monoHER and ICRF-187 on the antitumour activity of doxorucin. Control group: no treatment, Doxorubicin group: $8 \mathrm{mg} / \mathrm{kg}$ i.v., on days 0 and 7 , Doxorubicin + monoHER 5-day group: $500 \mathrm{mg} / \mathrm{kg}$ i.p., days $0-4$ and $7-11$ (monoHER on days 0 and 7 were given $1 \mathrm{~h}$ prior to doxorubicin), Doxorubicin + monoHER 2 day group: $500 \mathrm{mg} / \mathrm{kg}$ i.p., days 0 and 1 and 7 and 8 (monoHER on days 0 and 7 were given $1 \mathrm{~h}$ prior to doxorubicin), Doxorubicin + ICRF-187 group: $100 \mathrm{mg} / \mathrm{kg}$ ICRF i.p., days 0 and 7 (ICRF-187 was given $1 \mathrm{~h}$ prior to doxorubicin), MonoHER 5-day group: $500 \mathrm{mg} / \mathrm{kg}$ i.p., days 0-4 and 7-11 without doxorubicin

neutrophil influx at both 6 and $24 \mathrm{~h}$ after reperfusion by $58 \%$ and $49 \%$, respectively.

\section{Clinical studies}

A phase I human volunteer i.v. dose of monoHER escalation study was performed in order to find the maximal plasma concentration $\left(C_{\max }\right)$ and the area under the plasma concentration time curve $\left(\mathrm{AUC}^{\infty}\right)$ as observed in mice after administration of the protecting dose of $500 \mathrm{mg} / \mathrm{kg}$ monoHER i.p. The study was performed as a single blind, randomized trial in healthy volunteers (age between 19 and 56 years). At each dose level, six subjects received monoHER and three placebo. MonoHER was solubilized in $100 \mathrm{ml}$ dextrose $5 \%$ and administered as an i.v. infusion in $10 \mathrm{~min}$. The placebo consisted of $100 \mathrm{ml}$ dextrose $5 \%$. The i.v. starting dose in human volunteers of monoHER was $100 \mathrm{mg} / \mathrm{m}^{2}$. Dose escalation by $100 \%$ of the preceding dose took place after finishing each dose level until the protecting pharmacokinetic values for $C_{\max }$ and $\mathrm{AUC}^{\infty}$ (as observed in mice after $500 \mathrm{mg} / \mathrm{kg}$ monoHER i.p.) were reached and/or serious side effects were observed. The dose was escalated up to $1500 \mathrm{mg} / \mathrm{m}^{2}$. The mean values of $C_{\max }$ and $\mathrm{AUC}^{\infty}$ were $360 \pm 69.3 \mu \mathrm{M}$ and $6.8 \pm 2.1 \mu \mathrm{mol} \mathrm{min} / \mathrm{ml}$, respec- tively. These values were comparable to the $C_{\max }$ and $\mathrm{AUC}^{\infty}$ observed under the protecting conditions in mice. No serious side effects occurred during the entire study. From this phase I study it could be concluded that $1,500 \mathrm{mg} / \mathrm{m}^{2}$ is a feasible and safe dose to be evaluated in a phase II study to investigate the protective properties of monoHER against doxorubicin-induced cardiotoxicity in cancer patients [17]. This phase II study is currently conducted.

\section{References}

1. Goeptar, A. R., Te Koppele, J. M., Lamme, E. K., Piqué, J. M., \& Vermeulen, N. P. E. (1993). Cytochrome P450 2B1-mediated one-electron reduction of adriamycin: A study with rat liver microsomes and purified enzymes. Molecular Pharmacology, 44, 1267-1277.

2. Creighton, A. M., Hellmann, K., \& Whitecross, S. (1969). Antitumour activity in a series of bisketopiperazines. Nature, 222, 384-385.

3. Holcenberg, J. S., Tutsch, K. D., Earhart, R. H., Ungerleider, R. S., Kamen, B. A., Pratt, C. B., Gribble, T. J., \& Glaubiger, D. L. (1986). Phase I study of ICRF-187 in paediatric cancer patients and comparison of its pharmacokinetics in children and adults. Cancer Treatment Reports, 70, 703-709.

4. Decorti, G., Bartoli Klugmann, F., Mallardi, F., Klugmann, S., Benussi, B., Grill, V., \& Baldini, L. (1983). Effects of ICRF 159 on adriamycin-induced cardiomyopathy in rats. Cancer Letters, 19, 77-83.

5. Perkins, W. E., Schroeder, R. L., Carrano, R. A., \& Imondi, A. R. (1982). Effect of ICRF-187 on doxorubicin-induced myocardial effects in the mouse and guinea pig. British Journal of Cancer, 46, 662-667.

6. van Acker, S. A. B. E., van den Berg, D.-J., Tromp, M. N. J. L., Griffioen, D. H., van Bennekom, W. P., van der Vijgh, W. J. F., \& Bast, A. (1996a). Structural aspects of antioxidant activity of flavonoids. Free Radical Biology \& Medicine, 20, 331-342.

7. van Acker, S. A. B. E., van den Berg, D.-J., Tromp, M. N. J. L., Griffioen, D. H., van Bennekom, W. P., van der Vijgh, W. J. F., \& Bast, A. (1996b). A quantum chemical explanation for the antioxidant activity of flavonoids. Chemical Research in Toxicology, 9, 1305-1312.

8. van Acker, S. A. B. E., Plemper van Balen, G., van den Berg, D.J., Bast, A., \& van der Vijgh, W. J. F. (1998). Influence of iron chelation on the antioxidant activity of flavonoids. Biochemical Pharmacolgy, 56, 935-943.

9. van Acker, S. A. B. E., Voest, E. E., Beems, D. B., Madhuizen, H. T., de Jong, J., Bast, A., \& van der Vijgh, W. J. F. (1993). Cardioprotective properties of O-(beta-hydroxyethyl)-rutosides in doxorubicin-pretreated BALB/c mice. Cancer Research, 53, 4603-4607.

10. Voest, E. E., van Acker, S. A. B. E., van der Vijgh, W. J. F., van Asbeck, B. S., \& Bast, A. (1994). Comparison of different iron chelators as protective agents against acute doxorubicin-induced cardiotoxicity. Journal of Molecular and Cellular Cardiology, 26, 1179-1185.

11. Hüsken, B. C. P., de Jong, J., Beekman, B., Onderwater, R. C. A., van der Vijgh, W. J. F., \& Bast, A. (1995). Modulation of the in vitro cardiotoxicity of doxorubicin by flavonoids. Cancer Chemotherapy and Pharmacology, 37, 55-62.

12. van Acker, S. A. B. E., Kramer, K., Grimbergen, J. A., van den Berg, D.-J., van der Vijgh, W. J. F., \& Bast, A. (1995). Monohydroxyethylrutoside as protector against chronic doxorubicin- 
induced cardiotoxicity. British Journal of Pharmacology, 115, 1260-1264.

13. van Acker, S. A. B. E., Boven, E., Kuiper, K., van den Berg, D.-J., Grimbergen, J. A., Kramer, K., Bast, A., \& van der Vijgh, W. J. F. (1997). Monohydroxyethylrutoside, a dose dependent cardioprotective agent, does not affect the antitumor activity of doxorubicin. Clinical Cancer Research, 3, 1747-1754.

14. Kaiserova, H., den Hartog, G. J. M., Simunek, T., Schoterova, L., Kvasnickova, E., \& Bast, A. (2006). Iron is not involved in oxidative stress-mediated cytotoxicity of doxorubicin and bleomycin. British Journal of Pharmacology, 149, 920-930.

15. Abou El Hassan, M. A. I., Verheul, H. M. W., Jorna, A. S., Schalkwijk, C., van Bezu, J., van der Vijgh, W. J. F., \& Bast, A.
(2003). The new cardioprotector monohydroxyethylrutoside protects against doxorubicin-induced inflammatory effects in vitro. British Journal Cancer, 89, 357-362.

16. de Celle, T., Heeringa, P., Strzelecka, A. E., Bast, A., Smits, J. F., \& Janssen, B. J. (2004). Sustained protective effects of 7 monohydroxyethylrutoside in an in vivo model of cardiac ischemia-reperfusion. European Journal of Pharmacology, 494, 205-212.

17. Willems, A. M., Bruynzeel, A. M., Kedde, M. A., van Groeningen, C. J., Bast, A., \& van der Vijgh, W. J. F. (2006). A phase I study of monohydroxyethylrutoside in healthy volunteers. Cancer Chemotherapy and Pharmacology, 57, 678-684. 